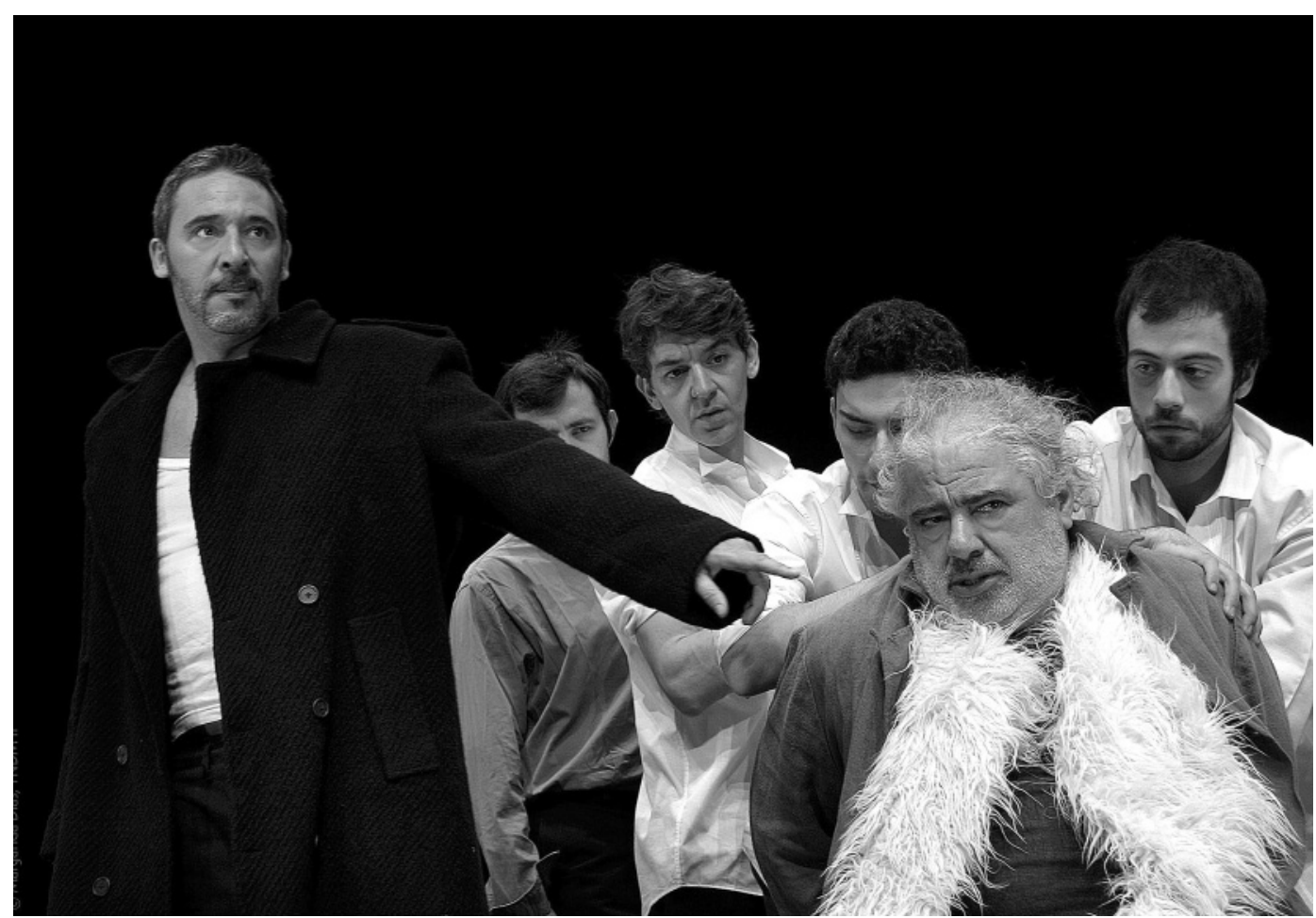

\title{
Édipo no Teatro Nacional Pela mão de Jorge Silva Melo
}

\section{José Pedro Serra}

Titulo: Rei Édipo (427 a.c.). Autor: Sófocles. Acompanhamento dramatúrgico: José Pedro Serra. Versão e encenação: Jorge Silva Melo. Cenografia e figurinos: Rita Lopes Alves. Música original: Pedro Carneiro. Espacialização e assistência musical: André Sier. Luz: Pedro Domingos. Caracterização especial: João Prazeres. Interpretação: Diogo Infante, Lia Gama, Virgilio Castelo, António Simão, Cândido Ferreira, José Neves, António Banha, Pedro Gil, Américo Silva, André Patricio, Bernardo Almeida, Daniel Pinto, David Pereira Bastos, Elmano Sancho, Estêvão Antunes, Hugo Bettencourt, Hugo Samora, João Meireles, João Miguel Rodrigues, João Delgado, Joaquim Pedro, John Romão, Manuel Sá Pessoa, Miguel Telmo, Miguel Aguiar, Pedro Lamas, Pedro Luzindro, Pedro Cardoso, Pedro Mendes, Ricardo Batista, Ruben Tiago, Tiago Matias, Tiago Mateus; as crianças: Beatriz Lourenço e Neuza Campos / Beatriz Monteiro e Margarida Correia / Inês Antunes e Inês Constantino; os músicos: Ângela Carneiro, David Silva, Marco Fernandes. Co-produção: Teatro Nacional D. Maria II / Artistas Unidos em colaboração com a Orquestra de Câmara Portuguesa. Local e data de estreia: Lisboa, Teatro Nacional D. Maria II, Sala Garrett, 18 de Fevereiro de 2010.

A tragédia grega levanta múltiplos e difíceis problemas. Genericamente, não é dificil identificar as causas de onde tais problemas derivam: a distância cultural e religiosa existente entre a Grécia clássica e o nosso tempo; a concepção grega do espaço teatral, indissoluvelmente ligado ao sentido da representação e muito diferente dos modernos espaços teatrais; a dimensão cívica e política da tragédia grega; a forte presença da retórica - nas esticomitias (diálogos intensos e de curtas falas) ou nas rhesis (longas tiradas das personagens) - isto é, dito de outra forma, o tipo de linguagem utilizada na tragédia. Cada um destes factores explode em inúmeras questões concretas (texto, cenário, papel do coro...) que o encenador não pode evitar e tem de resolver. Do modo como estas dificuldades se resolvem resulta a acuidade ou o falhanço da representação.

Em Fevereiro passado, pela mão de Jorge Silva Melo, o Teatro Nacional levou à cena uma versão do Rei Édipo de Sófocles. Como foram, então, aí tratadas algumas das dificuldades a que atrás nos referimos? Tal pergunta coloca-nos, creio, numa ajustada perspectiva para a compreensão e para o comentário desta representação.

Comecemos pelo texto que representa desde logo a dificuldade inicial. Que tipo de texto apresentar? Que tradução escolher ou que tipo de tradução forjar? Do texto de Sófocles se pode dizer o que em geral se diz de toda a poesia, que em sentido estrito é intraduzivel e que toda a tradução, por melhor que seja, representa uma tentativa falhada. Do que se trata aqui, porém, não é da antiquíssima questão do traductor traditor, mas da escolha primeira entre mantermo-nos muito próximo do texto original, no espírito e na letra, pagando um alto preço dramático pelo rigor dessa proximidade literária, ou, ao contrário, distanciarmo-nos o suficiente do texto, sem lhe perder o pulso, de forma a reforçar a compreensão e a intensidade dramática para o espectador de hoje. Onde repousar a
José Pedro Serra é Professor do Departamento de Estudos Clássicos da Faculdade de Letras da Universidade de Lisboa e investigador do Centro de Estudos Clássicos da mesma Faculdade. 


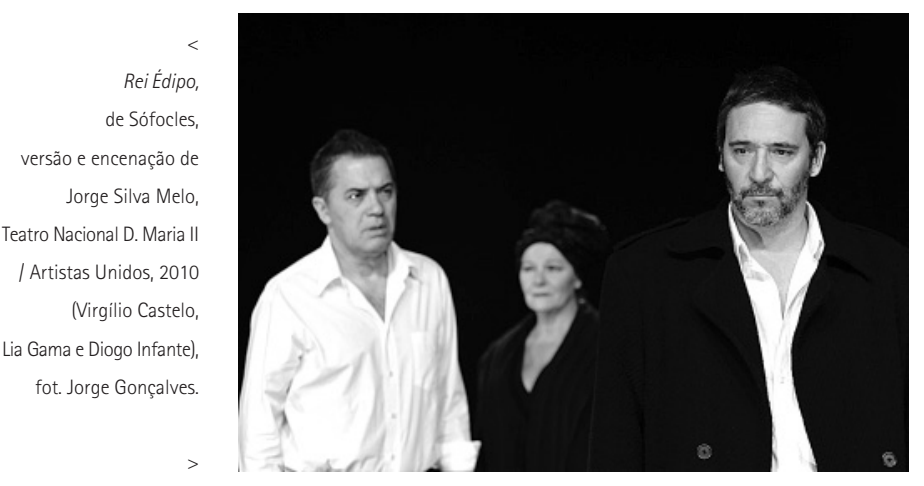

Rei Édipo,

de Sófocles,

versão e encenação de

Jorge Silva Melo,

Teatro Nacional D. Maria II

| Artistas Unidos, 2010

(Pedro Luzindro,

Tiago Matias, Pedro Lamas

e Pedro Gil),

fot. Margarida Dias.

nossa lealdade última: no literal respeito ao texto, ou na inegociável atenção ao espectador a quem texto e acção se dirigem? Poder-se-ia dizer do texto apresentado por Jorge Silva Melo - não propriamente uma tradução mas uma versão ou uma conversão, como ele próprio lhe chama - que obedece a três ideias fundamentais, harmonicamente concorrentes: purificação, clarificação, intensidade dramática. Não contém, obviamente, a purificação nenhum conteúdo moral; consiste ela simplesmente na expurgação de elementos laterais e menos significativos cuja apreensão seria fácil para os cidadãos de Atenas, mas que para o público de hoje representariam um ruido dispersante. Neste caso, estão, por exemplo, referências geográficas completamente obscuras para a maioria dos espectadores de hoje. Esta eliminação de "elementos distractivos", a que chamei purificação, concorda com a intenção de "clarificar" a acção, isto é, a de apresentar o drama na força pujante das suas tensões e dos seus múltiplos e inquietantes sentidos, sem que ao espectador seja concedido o pretexto da dormência resultante de uma alienante estranheza. Resulta a referida "clarificação" de dois factores que me parecem cruciais: em primeiro lugar a cuidada tradução de conceitos gregos para a linguagem de hoje, de modo a que essa transposição conceptual não se erga majestosa do ponto de vista da erudição e da literatura, mas pobre do ponto de vista teatral, e, em segundo lugar, a hábil aplicação da arte da repetição. No primeiro caso, podemos citar o exemplo da noção de miasma. Trata-se efectivamente de um termo de grande significado na cultura grega e de importância relevante no Rei Édipo, uma vez que traduz a poluição que, ali nascida e ali alimentada, devasta Tebas - óbvia referência ao assassínio de Laio, ao parricídio e ao incesto. As traduções habituais e mais rigorosas para o grego miasma são mancha poluição ou simplesmente miasma. Este, porém, é um termo difícil e "poluição" e "mancha", nas sociedades idealmente ecológicas como as nossas, desviam-nos do sentido primeiro. Jorge Silva Melo preferiu traduzir a ideia por "limpar a terra do mal que a conspurca" tornando-a clara ao auditório, sem a desfigurar. No segundo caso, o que designei por "arte da repetição" encontra-se presente ao longo de todo o texto, quer na fala das personagens, quer na intervenção do coro ("Édipo - Pedra seria eu, / pedra, / se não tivesse piedade / desse vosso sofrimento." "Coro - Sofrem, sofrem os homens, / deuses. / Deuses, / tende piedade. / Estão doentes os soldados, / estão doentes os homens."). 0 efeito destas repetições é imenso. De acordo com a intenção do autor, impede que nos refugiemos na pretensa doçura do verso grego, expondo-nos antes ao "ritmo martelado" de um verso que nos expõe a "melódicas

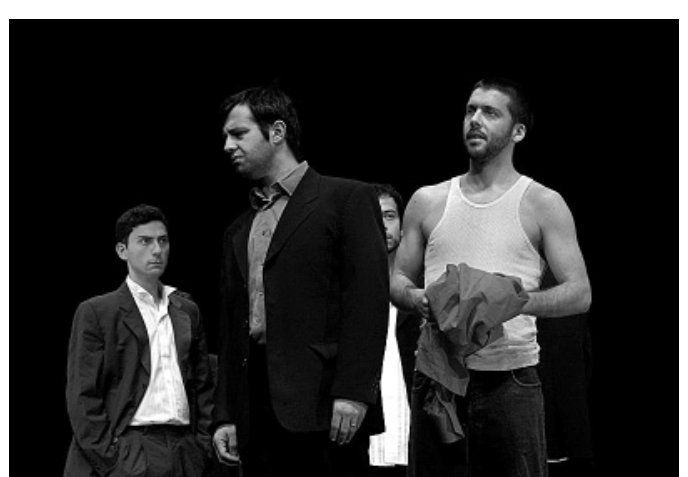

facadas". E de modo nenhum se perdeu intensidade poética; pelo contrário, e paradoxalmente, se alguma crítica se poderia fazer, consistiria ela na afirmação de uma tal pujança lírica que pode ter esbatido a distinção entre as intervenções intrinsecamente líricas do coro e as intervenções mais prosaicas dos actores. As repetições concorrem ainda para um reforço do pathos, para a expressão exacerbada dos sentimentos e da gravidade da acção, fortalecendo a intensidade do drama. Desta forma purificação, clarificação, intensidade dramática são os princípios que determinam a arquitectura deste texto. Importa, contudo, realçar, que esta versão mantém uma notável fidelidade à obra de Sófocles, na ambiguidade talvez aporética - que a caracteriza, na força das suas inquietações não resolvidas. Exemplo claro dessa fidelidade está no modo cuidado e restrito como utiliza a categoria da "vontade" (e o verbo querer...), categoria para nós tão próxima e imediata mas de muito discutível aplicação à tragédia grega.

0 coro constitui um dos maiores problemas na encenação contemporânea do teatro grego. A prova do embaraço dos encenadores em lidar com esse corpo colectivo reside no facto de não raramente o suprimirem ou o transformarem em actor entre actores, singularizando-o. $\mathrm{Na}$ base desta normalmente empobrecedora opção está a dificuldade em encontrar o espaço teatral apropriado para as suas movimentações (o correspondente ao grande espaço circular dos teatros gregos, designado por orquestra) e ainda a perda da ressonância política que o atravessa. A manifesta autoridade do coro - qualquer que seja o modo como se compreenda o seu estatuto e a sua função - vem-Ihe pela ligação profunda à voz da cidade e à dimensão religiosa da polis, não tanto em sentido estritamente ideológico, mas como recorte do horizonte colectivo, e portanto político, fora do qual o cidadão ateniense não compreende a sua acção. Por isso o coro não é propriamente um actor, mas um comentador, um mediador do que na skene, na "cena", se passa, e nas suas intervenções lateja o conflito entre o colectivo e o individual entre os homens e os deuses. 0 afastamento dos deuses, a astenia da nossa vida política, bem como a perda do sentido da coisa comum tornam dificil a incorporação do coro.

Um dos aspectos interessantes desta representação reside justamente no tratamento dado ao coro. Fundamentalmente, é no espaço em frente à porta do palácio, lugar da palavra argumentativa e lugar da manifestação de medos e anseios, que o coro encontra o espaço para a expressão da sua voz colectiva. A força dramática enraíza-se, sobretudo, nesse poderoso espaço central. Todavia, o alargamento do espaço de evolução 


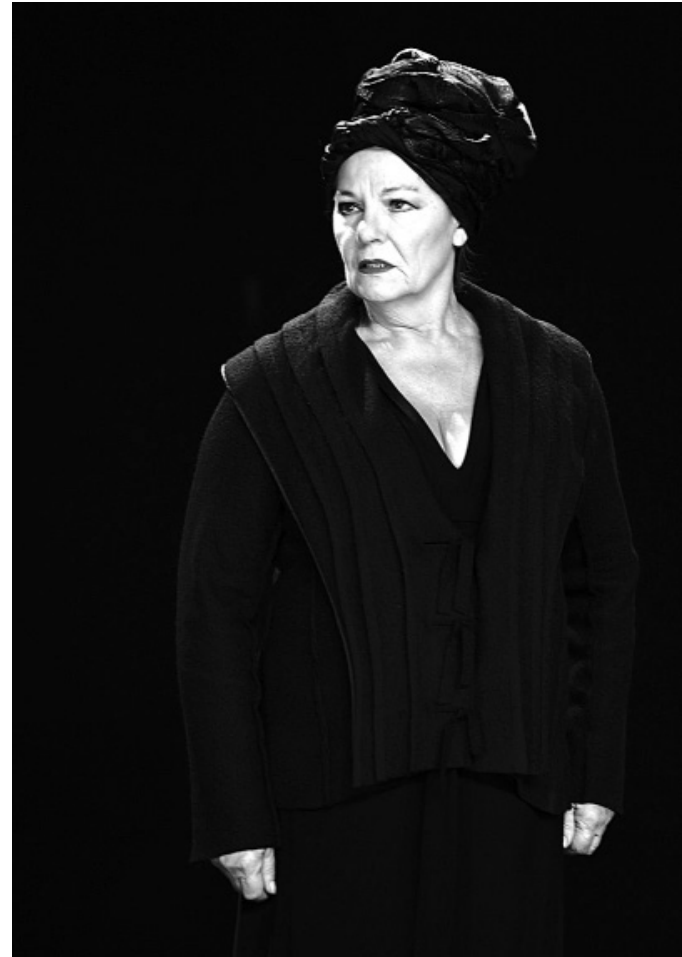

dos elementos do coro para as coxias laterais da plateia - curiosamente numa forma quase semi-circular -, envolvendo os espectadores, deu uma enorme profundidade e ressonância às intervenções do coro. Para isso contribuiu também, e muito, a forma ondulante das falas do coro, como se nelas se cantasse a várias vozes. Aos versos sincopados dos actores respondia uma marulhante onda de vozes. E o resultado teatral foi poderoso.

A propósito, diga-se ainda que a utilização das coxias da plateia permitiu ainda resolver um outro problema já não relacionado com o coro. Refiro-me às demoradas entradas em cena de Creonte e do pastor vindo de Corinto, cuja ilusão dramática é muito mais fácil de resolver no espaço aberto do teatro grego. Saliente-se, porém, que em nenhum momento se perdeu a noção da centralidade do espaço, tal como atrás referi. A cenografia, de resto, seguindo a tradicional presença de uma porta central, respeitou, e a meu ver bem, a tensão entre o que se dá a ver e o que se esconde, o que se passa fora do palácio e o que se passa dentro do palácio, onde Jocasta se suicida e Édipo se cega. E não é possível nem desejável escamotear esta tensão.

A representação das personagens da tragédia grega constitui para os actores uma prova de imenso risco. A provação por que passam resulta em parte do abandono em que se encontram - como alguém já disse, não se podem refugiar no cigarro, no telefone, na cadeira que puxam ou na gaveta que abrem. Mas mais dificil do que isso é encontrar o registo próprio para a manifestação das emoções e para aplicação da retórica. Um dos maiores desastres é, para mim, transformar a excêntrica e cósmica tragédia grega no drama psicológico burguês. Ora isso não aconteceu. Édipo, Jocasta e Creonte mostraram, por vezes com violência, o pathos que atravessa as personagens e, mau grado a retórica das longas tiradas e das esticomitias, Diogo Infante, Lia Gama e Virgilio Castelo não perderam de vista a gravidade dos seus papéis. Dir-se-ia que os seus

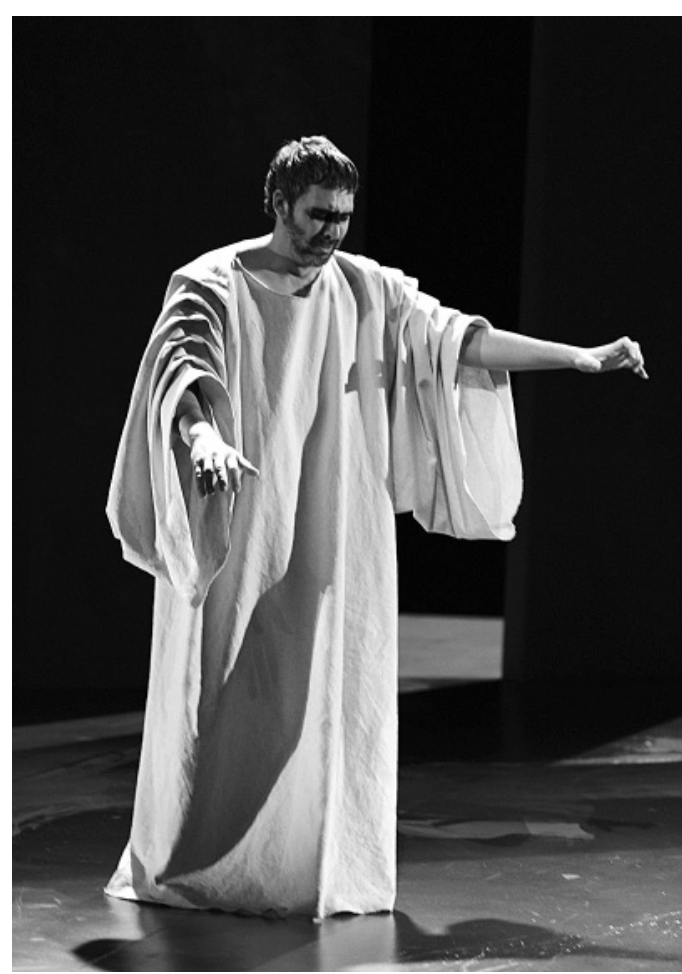

ReiÉdipo,

de Sófocles,

versão e encenação de

Jorge Silva Melo

Teatro Nacional D. Maria I

| Artistas Unidos, 2010

(< Lia Gama:

$>$ Diogo Infante),

fot. Jorge Gonçalves. lamentos e as suas cóleras não se transformaram em desabafos ou em irritações porque nunca se centraram em si próprios, desligados dos deuses e do destino (recordese a fala de Édipo cego ou a silenciosa saida de cena, imediatamente antes do suicidio de Jocasta). A intervenção do mensageiro (António Banha) deve também ser referida. É muito ingrata a representação do mensageiro.

Personagem indispensável para o espectador fazer a ligação entre o que vê e o que se não vê, a verdade é que as intervenções do mensageiro parecem muitas vezes metidas à força, formalmente irrelevantes e até prejudiciais ao pathos trágico. Deve, porém, dizer-se, que, neste caso, a intervenção do mensageiro foi plenamente conseguida, de modo nenhum quebrando o ritmo da acção e

contribuindo até para a intensificação da emoção trágica.

Na saudável austeridade do movimento dos actores, um gesto me pareceu deslocado. Refiro-me ao beijo trocado por Jocasta e Édipo no momento em que as inquietações pareciam poder dissolver-se. Para a minha sensibilidade, esse beijo de recorte não propriamente erótico mas nascido de uma habitualidade conjugal introduz uma nota de familiaridade, de banalidade quotidiana e doméstica, dissonante da gravidade cósmica da acção. Se bem entendi, Jorge Silva Melo deixou os actores agirem, respeitando neste caso a naturalidade de um impulso que os guiou. Pergunto-me, porém, se este gesto não é demasiado familiar, enfraquecendo até a dimensão da questão sexual que os une.

Ainda duas palavras. Uma respeitante aos figurinos. Interessante e conseguida a mistura entre os modernos fatos e o manto antigo de Édipo, apontando para uma fértil mistura de tempos.

Apropriada, muito apropriada me pareceu a música de Pedro Carneiro. Desconhecendo como era a música (e a dança...) na tragédia grega, e não procurando por isso imitar nada, a percussão foi boa escolha e o resultado foi forte. Tocou ao ritmo da mão criadora de Jorge silva Melo. 